\title{
The socio-economic impact of the Karoo National Park
}

Authors:

Melville Saayman ${ }^{1}$

Andrea Saayman ${ }^{1}$

Madelien Ferreira ${ }^{1}$

\section{Affiliations:}

${ }^{1}$ Institute for Tourism and

Leisure Studies, School of

Economics, North West

University, South Africa

\section{Correspondence to:}

Melville Saayman

e-mail:

melville.saayman@nwu.

ac.za

\section{Postal address:}

Private Bag X6001,

Potchefstroom, 2520

Keywords:

SANParks; South Africa; tourism; economic value; community perceptions

\section{Dates:}

Received: 10 Aug. 2008

Accepted: 11 Nov. 2008

Published: 05 May 2009

How to cite this article: Saayman, M., Saayman, A. \& Ferreira, M., 2009, 'The socio-economic impact of the Karoo National Park', Koedoe 51(1), Art. \#158, 10 pages. DOI: $10.4102 /$ koedoe.v51i1.158

\section{This article is available} at: http://www.koedoe.co.za

(C) 2009. The Authors. Licensee: OpenJournals Publishing. This work is licensed under the Creative Commons Attribution License.

\section{ABSTRACT}

National parks in South Africa are seen as major tourism assets due to the wildlife and various activities for international and local visitors. Little is known of the socio-economic contribution of these parks to their respective local economies. The purpose of this research was to determine the socio-economic impact of the Karoo National Park (Karoo NP) in South Africa, especially the economic impact of the Karoo NP on the local economy, the impact of tourism business development in the Karoo district, and how the park affects the community. Three surveys were used to determine the socio-economic impact: a community survey, a business survey and a tourist survey. The results show that the park has an impact in terms of production, income generation and employment in the area, but this impact is not as significant as that of other national parks in South Africa. A small percentage (4\%) of businesses in Beaufort West owe their existence to the Karoo NP, but most rely on tourist spending. For the park to have a greater impact, it is imperative to increase accommodation capacity, offer more activities and promote activities and attractions in the region.

Conservation implication: The importance of this article lies in the economic value that conservation management generates as well as identifying the benefits that communities derive from the existence of a national park. It also supports the notion that conservation entails more than just conserving fauna and flora and highlights the interdependence of conservation, tourism and community participation.

\section{INTRODUCTION}

National parks in South Africa have three fundamental spheres: firstly, to conserve the biodiversity of the country; secondly, to maintain a relationship of community upliftment and capacity building with people living in the areas in and around the parks; and, lastly, to provide a recreational outlet for people to experience and enjoy the wonders of the parks (Saayman \& Saayman 2006a).

While the main emphasis of national parks has traditionally been on conservation, there has been a shift towards economic sustainability and the upliftment of local communities (Myburgh \& Saayman 2002). It is the latter that provides the rationale for this research and, although South Africa has some of the greatest protected areas in the world, little is known about the socio-economic impact of these parks.

Socio-economics is the study of the relationship between economic activity and social life (Van der Merwe 2008). The goal of a socio-economic study is generally to assess socio-economic development, usually in terms of improvements in metrics such as gross domestic product (GDP), life expectancy, literacy and levels of employment (Van der Merwe 2008), with the aim of enhancing the benefits received by the society. A socio-economic impact study therefore goes beyond assessing income generated by the park, and also involves the contribution of the park to the quality of life of the community (Saayman \& Saayman 2006a).

Eadington and Redman (1991, cited by Walpole \& Goodwin 2000) state that tourism, as a development tool, holds many potential economic benefits for host communities, including increased employment opportunities, improved socio-economic conditions and greater market stability than are provided by traditional commodity exports. The magnitude of the economic benefits is dependent on the amount that remains in the area. Adding to this, Saayman and Saayman (2004) express their concern about leakages, both in the form of imported goods and imported skills, which will reduce the benefit for the local community because most national parks are situated in rural areas.

Page (2007) identified four economic benefits of tourism, namely the generation of income for the local community; the creation of new employment opportunities; improvements to the structure and balance of economic activities in the locality; and the encouragement of entrepreneurial activity. The attitudes of residents towards tourism represent an important way in which participants contribute to policy and public support for, or dissent towards, tourism (Page 2007).

Studies that were conducted on socio-economic and economic impacts include those of Loader (1994) and Pelser (2003), who argue that social involvement is an integral part of conservation in South Africa. Macleod (2001) and Fauzi and Buchary (2002) suggest that the alleviation of poverty and marginality in the case of residents of the Kepulauan Seribu Marine Park, Del Este in the Dominican Republic, should receive priority, and that park management should be based on consensus building and participation by all stakeholders. Therefore, the community should play an important role in maximising the local socio-economic benefits (Govender et al. 2005). An example of how the local community has focused efforts on maximising benefits from tourism activity as the result of a national park can be found in Mpumalanga Province. There, towns adjacent to the Kruger National Park have started to focus on offering additional tourism products, which contribute to income and employment and thereby increase the impact of the Park in the region (Saayman \& Saayman 2006b).

The Karoo National Park (Karoo NP) is located in the Western Cape Province of South Africa, on the outskirts of the town of Beaufort West, and can be accessed via the N1 highway. The Karoo NP 


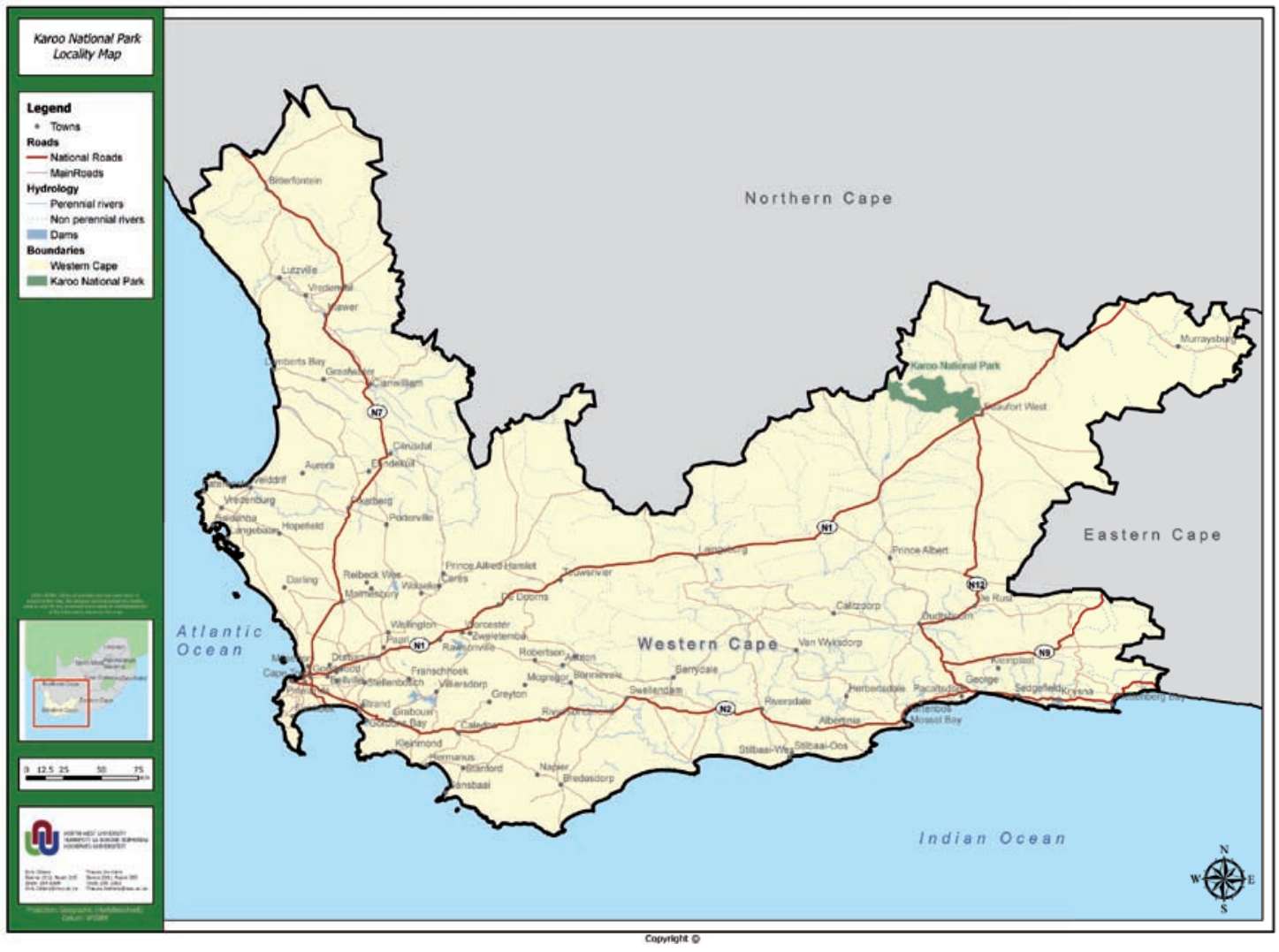

FIGURE 1

Location of Karoo National Park (Source: South African National Parks 2007)

serves mainly as an overnight park for visitors and tourists en route from or to the Western Cape/Gauteng Province (Figure 1). During the late 1950s, Mr William Quinton, a local farmer and keen birdwatcher, began campaigning to have a conservation area declared in the vicinity of Beaufort West. In the 1970s, the South African National Parks Board put forward plans to establish a national park that would be representative of the Karoo Biome. After considering a number of potential suitable areas, it was decided that this new park would be established in the vicinity of Beaufort West (South African National Parks 2007). The Town Council of Beaufort West donated 7209 ha of vacant communal land northwest of the town to the South African National Parks Board (currently known as SANParks). This formed the nucleus of the Karoo NP, proclaimed in 1979. Since then, additional land purchases have increased the Karoo NP to its present size of approximately 96000 ha (South African National Parks 2007)

The aim of this research was to estimate the socio-economic contribution of the Karoo NP to the surrounding communities, with an additional focus on the community's involvement in the Karoo NP, guided by the following questions:

- What is the economic impact of the Karoo NP on the local economy?

- What percentage of business development in the region is as a result of the park?

- How many people are employed as a result of tourism activity due to the Karoo NP?

- How satisfied is the community with regard to the Karoo NP?

\section{METHODS}

Saayman \& Saayman (2006a) created a framework to assess the socio-economic impact of national parks in South Africa (see Figure 2). They identified five issues of importance when assessing the socio-economic impacts of parks. Firstly, there must be an understanding of the area and the main economic activities in the area - the spatial area must therefore be specified and all the communities in the specified area should be included in the research. Secondly, the magnitude of visitor spending and the distribution of the spending throughout the local economy should be determined. This could be done via visitor (demand) and business (supply) surveys, especially in local areas, where business and spending information is not readily available. Thirdly, and if possible, these should be complemented by a community survey. Fourthly, the spending by the national park on employees and local products should be included to obtain a complete picture of spending activities resulting from the existence of the park. Fifthly, the social impact of the park on the community must be determined. In areas where no local input-output model is available (which is usually the case), a proportional multiplier analysis could be used to determine the values of the income and sales multipliers, and to estimate the economic impact of the national park on income and employment. Finally, the change in the nature of business and employment opportunities in the area due to the national park should be determined by comparing it to previous business surveys of the area (Saayman \& Saayman 2006a).

Based on the above, three surveys were conducted: a community survey, a business survey in Beaufort West and a visitor survey of tourists visiting the Karoo NP. Secondly, a partial input-output model was developed to estimate partial multipliers and thus the economic impact of the Karoo NP. In general, multipliers indicate the magnitude of economic benefits in terms of sales, income and employment generated by the initial spending in the economy due to the tourism activity. Input-output models are often used to generate these multipliers. Yet regional inputoutput tables are often not available (also in South Africa) and are expensive to develop because of the extensive data required. Because of these constraints, this research employs partial multiplier analysis, and the partial multipliers are derived from a simplified input-output table that was compiled from survey data - not regional estimates based on national input-output 


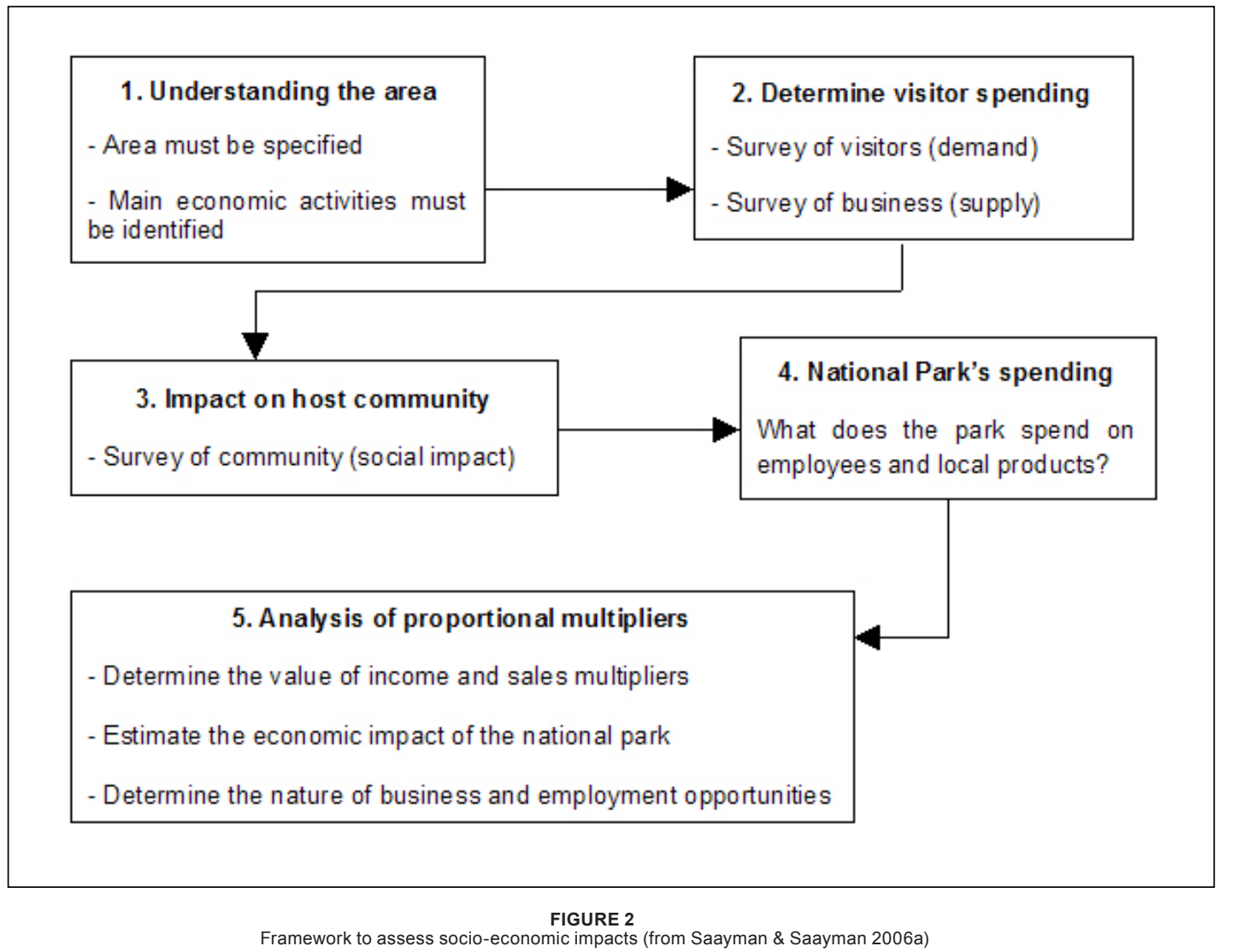

tables. Thirdly, descriptive analysis was used to determine how the community feels about the Karoo NP and to determine its effect on the community of Beaufort West.

The surveys were completed between 27 March 2007 and 1 April 2007. Seven postgraduate students were recruited to assist with the surveys. These fieldworkers distributed the questionnaires and collected the completed questionnaires later in the evening. Microsoft Excel was used to capture the data and data analyses were conducted using both Excel and SPSS. The statistical techniques that were used include descriptive analyses. These descriptive analyses helped to provide preliminary insights into the nature of the responses obtained, as reflected in the distribution of the values for each variable of interest (Tustin et al. 2005:341).

\section{The surveys}

\section{Survey one: Community survey}

A structured questionnaire served as the instrument to collect the data, which contained both descriptive and causal questions. According to Trochim (2006), descriptive research primarily describes what is occurring or what exists, whereas causal research investigates the effects of variables on one another. The questionnaire was based on the social impact measuring instrument developed by Fredline et al. (2003).

The questionnaire was adapted slightly to focus on the needs of the study. The main variables (residents' perceptions of the impacts of the National Park) were measured using a three- or four-point Likert scale (Fredline et al. 2003). Questions were used to measure the independent variables and demographic information as well. These variables included participation, community attachment and demographics (Fredline et al.2003). According to the 2006 census (StatsSA 2007) and the Department of Local Government and Housing (2006), there are approximately 5000 households in a $30 \mathrm{~km}$ radius in Beaufort West. Stratified sampling of 300 households was undertaken, and 240 questionnaires were usable. For the purpose of the article, only the relevant descriptive data are used.

\section{Survey two: Business survey}

The questionnaire used for the business survey was similar to the one used by Saayman and Saayman (2006a) to determine the socio-economic impact of the Addo Elephant National Park. Research boundaries were determined for the survey, which were as follows: a $30 \mathrm{~km}$ radius around the Karoo National Park, which included the town of Beaufort West. According to the Municipal Demarcation Board, South Africa (2006) there are a total of 757 businesses in Beaufort West. Most of the businesses that were surveyed were located in the town (see Figure 1). Convenience sampling was used for the business survey. In a convenience sample, the sample members are chosen on the basis of being readily accessible and willing to complete the questionnaire (Tustin et al. 2005). A total of 86 questionnaires were received, which gives an $11 \%$ response rate.

\section{Survey three: Visitor survey}

The questionnaire that was used has been applied in various national park visitor surveys in South Africa since 2001. In 2007, an availability sample was drawn from the visitors to the Karoo NP for the period (27 March 2007 to 1 April 2007). It must be noted that, for the purpose of this article, only overnight visitors formed part of the survey. A total of 104 questionnaires were received in this period, which is greater than the sample sizes of the previous years because the research team used a longer data collection period in 2007.

In 2007, 31469 people visited the Karoo NP. This visitor number includes both day visitors and overnight visitors. Since the Karoo NP offers camping facilities and chalets, the overnight visitors were further divided into campers and visitors that spent the night in chalets. In terms of overnight visitors, 13449 camping person nights and 9373 chalet unit nights were sold. If it is taken into account that the average size of a visiting group 
to the Karoo NP was 3.14, the 104 questionnaires received represent 327 visitors to the Park during the year.

Factors that have an influence on the number of questionnaires completed during the survey period include that the Park has only 36 chalets and the bed occupancy varies between seasons, which makes it difficult to collect large samples during a short span of time. A larger sample requires longer survey periods, and this has significant budgetary implications.

The surveys conducted since 2001 were done in different months and therefore different seasons. Coupled to that, Saayman and Fouché (2007) indicated in an analysis of all surveys conducted at national parks in South Africa since 2001 that the profile stayed consistent, especially in the case of the Karoo NP. Therefore, the sample can be seen as being representative of the total population.

\section{Economic impact analysis}

As mentioned previously, the economic impact analysis consisted of compiling a partial input-output model and partial multipliers. In general, an input-output table formalises the relationship between industry inputs and its outputs into technical relationships. Leontief (United Nations 1999) introduced the fixed-coefficient linear production function, where the output of an industry is related to its inputs, assuming that the inputs are used in fixed amounts (therefore the fixed coefficients). Every sector's total output is a linear function of its intermediate output (i.e. products used by other industries) and final consumption output (i.e. products used by consumers). Mathematically, this can be expressed as follows:

$$
X_{1}=a_{11} X_{1}+a_{12} X_{2}+a_{1 n} X_{n}+F_{1}
$$

Where $X_{1}=$ output of sector $1 ; a_{11}, a_{12}, a_{1 n}=$ the amounts of these outputs that are used in other sectors as inputs (thus, the fixed coefficients), and $F_{1}=$ the amount of final output that is used by consumers. Equation 1 can also be shuffled to show how final demand, $F_{1}$, relates to total output and intermediate output:

$$
F_{1}=X_{1}-a_{11} X_{1}-a_{12} X_{2}-a_{1 n} X_{n}
$$

If the values of the coefficients are known, it is possible to determine the effect that a change in final demand will have on the level of output in the industry in which the demand changes. Via the linkages with other industries (the intermediate inputs used from other industries to produce the additional output) it can also be determined by how much the other industries output will change.

By nature, an input-output model makes certain assumptions. These assumptions include (UN 1999):

- Total input is equal to total output in each sector.

- Each coefficient is smaller than 1.

- The sum of all the coefficients should add up to 1 for every sector.

The partial input-output model compiled for the Beaufort West economy consists of only nine sectors - (i) accommodation, (ii) restaurants and food, (iii) curios, (iv) tourism services, (v) municipal services, (vi) transport services (including petroleum), (vii) retail, (viii) wholesale and (ix) manufacturing - to reflect the main spending items of tourists to the National Park. Since the partial inputoutput model was built based on survey data and not in-depth industry data, a number of simplifying assumptions were made.

First, since businesses are reluctant to give sensitive information regarding income and profit, some profit assumptions had to be made. The profit was calculated as a mark-up over stock and ranged from $20 \%$ (transport to, petroleum) to $50 \%$ (accommodation, curios). Second, to trace the purchases made by businesses, each business had to list its main suppliers of stock, services and other operational expenses. Since a further breakdown of the percentage of stock (for example) bought from a certain supplier was not given by the respondents, the assumption is made that the suppliers supply equal percentages. Third, since consumption data for Beaufort West is not available, the 2005 national input-output table consumption percentages are used to determine the income multipliers. Care was taken to include the coefficients of the industries that are pertinent in Beaufort West. Lastly, the municipal allocations were made in accordance with the Beaufort West Integrated Development Plan for 2007 (Nkungwana 2007).

The visitor and business surveys provided the information for the economic impact assessment. Yet, to get a clear picture of all spending as a result of the Karoo NP, SANParks provided the income and expense account for the Karoo NP for the year ending March 2007. According to this account, expenditure excluding depreciation amounted to approximately R5 million. A rough breakdown of these costs reveals that the highest spending item is personnel $(56.6 \%)$, followed by operational costs $(26.1 \%)$. To allocate these cost items to the various sectors in the model, some assumptions were again made, including that $30 \%$ of operational expenses are not incurred in the local area; maintenance cost is divided equally between retail, wholesale and manufacturing; all finance cost accrues to the local area; the remaining operational cost is divided between retail $(40 \%)$ municipal $(20 \%)$, transport $(20 \%)$, wholesale $(10 \%)$, food $(5 \%)$ and manufacturing (5\%); and $85.5 \%$ of personnel costs accrue to the local area (excluded are UIF and other insurance).

\section{RESULTS}

The results are discussed in three sections. In the first section, a brief overview is given of the descriptive results of the surveys. The second section contains the results of the economic impact study and section three contains the results of the social impact study.

\section{Descriptive results of the surveys}

The host community is mainly Afrikaans speaking and tourists are predominantly English speaking (Table 1). Both the host community and the visitors are in their mid to late forties. The community is not that well educated relative to the visitors. Both visitors and community members feel that the facilities at the Karoo NP meet their expectations. The visitors visit the Karoo NP for relaxation, whereas the community visits the Karoo NP to learn more about the animals and plants (wildlife, nature). The Karoo NP is also well known amongst various schools in Beaufort West, especially the previously disadvantaged schools, for the opportunities the learners have to visit the Park for educational reasons.

Four important pieces of information obtained from the visitor survey serve as input into the economic analysis. These are:

\section{Number of tourists (number of tourist groups)}

The visitor survey revealed that visitors to the Karoo NP travel in groups of 3.14, with campers travelling in larger groups (3.37) than visitors staying in chalets (2.89).

\section{Length of stay}

The average length of stay in the Karoo NP is 1.7 nights according to the visitor survey. Campers again tend to stay a bit longer - 1.94 nights, while visitors in chalets stay on average 1.49 nights. This is in line with previous surveys and the Karoo NP is therefore often seen as a stop-over destination between Cape Town and Gauteng.

\section{Expenditure by tourists}

According to the visitor survey, camping groups spend on average R570.92 while staying in the Karoo NP (See Table 2). 
TABLE 1
Profile of visitors and community members

\begin{tabular}{|c|c|c|}
\hline VARIABLE & OVERNIGHT VISITORS & COMMUNITY \\
\hline Gender & N/A & Female $(63 \%)$ and male $(37 \%)$ \\
\hline Language & Afrikaans (45\%), English (53\%), other (2\%) & Afrikaans (73\%), English (15\%), other (12\%) \\
\hline Average age & 48 years & 42 years \\
\hline Education & $98 \%$ have post-matric qualifications & $\begin{array}{l}56 \% \text { have a post-matric qualification } \\
40 \% \text { have matric }\end{array}$ \\
\hline Province of origin & $\begin{array}{l}\text { Gauteng (35\%), Western Cape (26\%); North-West } \\
(10 \%) \text {; KZN }(10 \%)\end{array}$ & Western Cape \\
\hline Times visited the park & On average, five times over the past three years & $\begin{array}{l}39 \% \text { visited the Park at least once, and } 61 \% \text { had not visited the } \\
\text { Park during March } 2006 \text { to March } 2007\end{array}$ \\
\hline Karoo NP effect on personal quality of life & N/A & $67 \%$ felt very positive; $30 \%$ indicated the Park had no effect \\
\hline Facilities & $50 \%$ had high expectations of the facilities in the Park & $\begin{array}{l}46 \% \text { felt the availability of facilities to local residents had increased, } \\
25 \% \text { indicated no change, } 12 \% \text { indicated a decrease, } 17 \% \text { were } \\
\text { not sure }\end{array}$ \\
\hline Reason for visiting the Karoo NP & $76 \%$ indicated that they visited the Park for relaxation & $83 \%$ visited the Park to learn more about animals and plants \\
\hline
\end{tabular}

TABLE 2
Spending per visitor group according to input-output categories

\begin{tabular}{|c|c|c|c|c|}
\hline SPENDING CATEGORY & VISITORS CAMPING & $\%$ & VISITORS IN CHALETS & $\%$ \\
\hline Accommodation & $\mathrm{R} 327.20$ & $57.3 \%$ & R673.35 & $76.3 \%$ \\
\hline Curios & $\mathrm{R} 12.42$ & $2.2 \%$ & R8.04 & $0.9 \%$ \\
\hline Food and restaurants & R107.20 & $18.8 \%$ & R119.53 & $13.5 \%$ \\
\hline Tourism services & $\mathrm{R} 65.40$ & $11.5 \%$ & R36.76 & $4.2 \%$ \\
\hline Retail & $\mathrm{R} 25.90$ & $4.5 \%$ & R5.68 & $0.6 \%$ \\
\hline Transport & R32.80 & $5.7 \%$ & R39.22 & $4.4 \%$ \\
\hline Municipal & Ro.00 & $0.0 \%$ & R0.00 & $0.0 \%$ \\
\hline Wholesale & $\mathrm{R} 0.00$ & $0.0 \%$ & $\mathrm{R} 0.00$ & $0.0 \%$ \\
\hline Manufacturing & R0.00 & $0.0 \%$ & R0.00 & $0.0 \%$ \\
\hline TOTAL & R570.92 & $100 \%$ & R882.58 & $100 \%$ \\
\hline
\end{tabular}

The spending by chalet tourists is on average R882.58 per group, exceeding that of campers. It is interesting to note that the spending patterns of campers differ substantially from those of visitors in chalets - this is evident from the percentages spent in each category. Transport to the Karoo NP is excluded from the analysis, as it cannot be ascertained where the car has been filled with fuel.

\section{Spending in the Beaufort West area}

Just over seventy (70.8) per cent of the respondents indicated that they spent money outside the Karoo NP in Beaufort West. Among the most prominent businesses visited by the respondents are petrol stations and supermarkets (retail/ food), followed by a variety of other businesses, including the butchery (food), restaurants, curio shops, other retailers (chemist, liquor store, bank), car repairs and the wholesaler Fruit and Veg. Table 3 presents a breakdown of the businesses in the area according to the business survey, as well as an indication of the employment levels and the number of permanent versus part-time personnel.

\section{Economic impact}

To derive total visitor expenditure the visitor numbers were used. Since unit nights already exclude the problem of "spending per person" versus "spending per group", only the number of campers is divided by the average group size for campers (3.37) to estimate the number of camper groups. According to this method, 3991 camper groups visited the Park in 2006/7. Table 2 indicates the magnitude of visitor spending, which was calculated by making use of the above estimates and the average spending per visitor group, as indicated in Table 4. It can be seen that visitor spending is estimated at approximately R10.5 million.

\section{Proportional multiplier analysis}

As suggested by Vaughan, Farr and Slee (2000), two methods can be employed to determine the economic impact on the local economy, namely iteration and matrix inversion. This research used the second method, matrix inversion, by which the nineby-nine matrix that was created was inverted to determine the effects of a change in demand on output (see Table 5). In terms of output, one additional tourist group (change in demand) in each category created the following additional output (see Eqn 1). To determine the total effect on income (direct, indirect and induced), the input-output table has to be expanded to include the effect of household spending and wages. In other words, a ten-by-ten matrix was created. The assumption was made that the consumption pattern of the locals in the study area is similar to that of the national consumption pattern (as defined 


\begin{tabular}{|c|c|c|c|c|}
\hline TYPE & NUMBER & Average number of EMPLOYEES & PERMANENT & PART-TIME \\
\hline Accommodation units & 5 & 15.6 & 14.2 & 1.4 \\
\hline Curio shop & 5 & 7.8 & 5 & 2.8 \\
\hline Food and restaurant & 11 & 12.7 & 9.5 & 3.2 \\
\hline Tourism services & 2 & 3.5 & 3.5 & 0 \\
\hline Retailers & 55 & 5.6 & 4.9 & 0.8 \\
\hline Transport and petrol stations & 4 & 34.3 & 27.3 & 7 \\
\hline Wholesalers & 3 & 25.7 & 22.7 & 3 \\
\hline Manufacturers & 4 & 5.7 & 4.7 & 1 \\
\hline
\end{tabular}

in the 2005 nationwide input-output table). It is evident that spending directly translates into income for a business and, as the business expands its production, the income of other businesses also expands. This process captures the direct and indirect effects of income for businesses. Not all income that businesses receive translates into income for consumers. The income is used to buy stock, pay for operational expenses and services, pay labourers, and for profits. What is more interesting to know is the latter - in other words, how does this translate into income for consumers (households) in the Beaufort West area? Therefore, we were only interested in finding the induced income effect of the additional spending. The results of the analysis are shown in Table 5.

It is also noteworthy that the income and output multipliers for the camping groups are lower than those of the chalets. This is to be expected, however, since campers spend less on accommodation (which is a labour-intensive activity) than groups in chalets and more on retail items and food - which is more capital-intensive and requires more stock purchases.

The change in output due to visitor spending in each industry in the proportional multiplier model is indicated in Table 6 . Also indicated in Table 6 is the business income (direct and indirect effect) generated due to one additional group.

If the above multipliers are applied to total spending by all visitors, the production and income effect of their spending would be as follows (Table 7):

While these estimates reflect the spending by visitors, the spending of the Karoo NP in its operations has not yet been reflected. If a similar process is repeated for Karoo NP expenditure (based on the allocations described above), the output multiplier for Karoo NP expenditure is 1.26, while the income multiplier is 0.88 . The total impact of the Karoo NP on the local economy is indicated in Table 8.

\section{Employment and business development}

The years that the different businesses have been in existence

\begin{tabular}{lcll} 
& \multicolumn{3}{c}{$\begin{array}{c}\text { TABLE 4 } \\
\text { Estimated total expenditure by visitor groups, } 2007\end{array}$} \\
\hline CATEGORY & $\begin{array}{l}\text { NUMBER OF } \\
\text { GROUPS }\end{array}$ & $\begin{array}{l}\text { AVERAGE } \\
\text { SPENDING PER } \\
\text { GROUP }\end{array}$ & $\begin{array}{l}\text { TOTAL } \\
\text { SPENDING }\end{array}$ \\
\hline Chalets & 9373 & R882.58 & R8 272 422 \\
Camping & 3991 & R570.92 & R2 278 542 \\
\hline TOTAL & 13364 & & R10 550 964 \\
\hline
\end{tabular}

(Source: Saayman \& Bothma 2007) gives a good indication of how business has developed in the region. The Karoo NP was founded in 1979. None of the accommodation units that are still available, curio shops or food and restaurant businesses are older than 28 years. Most are less than 15 years old, with only one curio shop and one restaurant being between 15 and 20 years old. It is also interesting that $78 \%$ of the retail stores are also younger than the Karoo NP, and that all the wholesalers and manufacturers that were surveyed have existed for less than 28 years. Only one transport business exceeds 28 years of existence.

Only $4 \%$ of the businesses indicated that they owed their existence to the Karoo NP. These businesses are all retailers. Many businesses indicated that they relied heavily on tourist spending (see Table 9), which might be an indication that the influence of the Karoo NP on tourism activity in the area is not taken into account by these businesses. It would be an interesting future study to examine whether the existence of the Karoo NP has changed tourism patterns to Beaufort West substantially (given that data would be available). Intuitively it has, since for many Beaufort West was initially just an overnight stop on the route between Cape Town and Johannesburg. Yet the visitor survey revealed that visitors to the Karoo NP spent on average almost two days in the Beaufort West area and most $(86 \%)$ of these visitors indicated that they also shopped in town. As indicated in Table 3, the accommodation industry is, as expected, very reliant on labour, with the five accommodation units providing employment for 78 people. This figure is put into perspective when it is compared to the 308 people working in the 55 surveyed retailers (see Table 3). It should be noted that, in $98 \%$ of the cases, the employed workers live in the area, which is encouraging, since employment opportunities are being created in Beaufort West, which has one of the highest rates of unemployment in the Western Cape.

On average, accommodation establishments sell $68 \%$ of their business to tourists and $32 \%$ to locals. The latter entails hiring of venues for meetings and conferences, as well as for catering. Tourists are also the main customers of tourism and recreation services, while transport businesses, restaurants and food stores, and curio shops are also very reliant on tourism for their existence. This is also indicated in Table 9, which shows that the Beaufort West economy is, in many respects, dependent on tourism for income and employment.

It is difficult to determine the exact number of jobs that can be ascribed to the existence of the Karoo NP. The Karoo NP itself employs 40 people, which is relatively few compared to other parks such as the Addo, Kruger and Tsitsikamma National Parks. The businesses also indicated the percentage of their turnover that they ascribed to the Karoo NP being in the vicinity. Guest houses and bed-and-breakfast establishments indicated that they owed $12 \%$ of their turnover to the Karoo NP. 


\begin{tabular}{llllll}
\multicolumn{7}{c}{$\begin{array}{c}\text { TABLE 5 } \\
\text { Multipliers }\end{array}$} \\
\hline CATEGORY & CHANGE IN DEMAND & CHANGE IN OUTPUT & CHANGE IN INCOME & $\begin{array}{l}\text { OUTPUT } \\
\text { MULTIPLIER }\end{array}$ & INCOME MULTIPLIER \\
\hline Chalet & R882.58 & R1 300.74 & R353.42 & 1.47 & 0.40 \\
Camp & R570.92 & R 818.34 & R211.35 & 1.43 & 0.39 \\
\hline
\end{tabular}

TABLE 6

Sectoral changes in output and income

\begin{tabular}{|c|c|c|c|c|}
\hline SECTOR & $\begin{array}{l}\text { CHALET: CHANGE IN } \\
\text { OUTPUT }\end{array}$ & $\begin{array}{l}\text { CHALET: CHANGE IN } \\
\text { INCOME }\end{array}$ & CAMP: CHANGE IN OUTPUT & CAMP: CHANGE IN INCOME \\
\hline Accommodation & 674.52 & 674.79 & 327.90 & 328.07 \\
\hline Curios & 8.04 & 13.34 & 12.42 & 15.74 \\
\hline Food and restaurants & 121.87 & 204.05 & 108.61 & 160.08 \\
\hline Tourism/recreation services & 37.34 & 60.80 & 65.75 & 80.45 \\
\hline Retail & 235.98 & 312.06 & 160.33 & 207.98 \\
\hline Transport & 82.44 & 115.93 & 55.42 & 76.39 \\
\hline Municipal & 84.45 & 104.07 & 50.97 & 63.26 \\
\hline Wholesale & 47.78 & 58.61 & 28.77 & 35.55 \\
\hline Manufacturing & 8.32 & 12.09 & 8.16 & 10.52 \\
\hline TOTAL & 1300.74 & 1555.75 & 818.34 & 978.06 \\
\hline
\end{tabular}

Impact of visitor Spend 7

ding on production and income

\begin{tabular}{llll}
\hline CATEGORY & $\begin{array}{l}\text { TOTAL } \\
\text { SPENDING }\end{array}$ & $\begin{array}{l}\text { OUTPUT } \\
\text { EFFECT }\end{array}$ & $\begin{array}{l}\text { INCOME } \\
\text { EFFECT }\end{array}$ \\
\hline Chalet & R8 272 422 & R12 160 460 & R3 308 969 \\
Camp & R2 278 542 & R3 258 315 & R888 631 \\
\hline TOTAL & R10 550964 & R15 418 775 & R4 197 600 \\
\hline
\end{tabular}

TABLE 8
Total impact of the Karoo National Park on the local economy

\begin{tabular}{llll}
\hline CATEGORY & $\begin{array}{l}\text { TOTAL } \\
\text { SPENDING }\end{array}$ & $\begin{array}{l}\text { OUTPUT } \\
\text { EFFECT }\end{array}$ & $\begin{array}{l}\text { INCOME } \\
\text { EFFECT }\end{array}$ \\
\hline Chalet & R8 272 422 & R12 160 460 & R3 308 969 \\
Camp & R2 278542 & R3 258 315 & R888 631 \\
Park & R4 187 378 & R5 276 096 & R3 684 893 \\
\hline TOTAL & R14 738 342 & R20 694 871 & R7 882 493 \\
\hline
\end{tabular}

Curio shops indicated that $8.8 \%$ of their business was due the Karoo NP, with restaurants indicating a figure of $15 \%$. Retailers and service stations also indicated that they respectively owed $8 \%$ and $20 \%$ of their turnover to the Karoo NP, and tourism and recreation services estimated this contribution at $15 \%$. If this is taken as an indication of the number of employment opportunities created due to the Karoo NP, it can be concluded that the Karoo NP led to only 102 job opportunities in the businesses surveyed (a linear relationship between turnover and employment is assumed).

The survey captured 142 beds as part of the accommodation sector, while the Beaufort West Tourism Association indicates that 300 beds are available. Thus, approximately $50 \%$ of the accommodation products were surveyed. If this proportion is true for all the business sectors, extrapolating the employment results would indicate that 204 additional jobs were created by the Karoo NP. With the direct employment by the Karoo NP, total employment is thus 244. Seen in the light that there are 7306 households in Beaufort West, it can be concluded that the Karoo NP, directly and indirectly, provides employment opportunities to $3.34 \%$ of all the households.

\section{Social impact}

The analysis of the social impacts of tourism is, however, affected by a number of elements, for example collective lifestyles, individual behaviour and family relationships. The following section focuses on the influence of the Karoo NP on the community and the role of the Karoo NP in Beaufort West. Table 10 gives the results of the influence of the park on the community by using a scale ranging from -3 , being very negative, to 3 , being very positive.

According to the respondents, the Karoo NP has a very positive impact $(72 \%)$ on the Beaufort West community. The Karoo NP also affects the community's personal quality of life positively $(67 \%)$ (Table 10). Therefore, the perception by the community of the way the Karoo NP influences them is overall very positive.

If one analyses the role that the Karoo NP plays in the Beaufort West community (Table 11), the respondents indicated that the appearance of the area had improved $(70 \%)$ due to the Karoo NP; the number of tourists visiting Beaufort West had increased $(68 \%)$; and the pride of the residents towards Beaufort West was positive $(65 \%)$. In general, the Karoo NP is seen as contributing to the upliftment of the area by adding to the tourism product offered by the area and improving people's perceptions of the area. All these aspects are positive.

\section{DISCUSSION}

Based on the results of the research conducted at the Karoo NP and among the businesses and community of Beaufort West, the following results were identified. 
TABLE 9

Employment and other ratios

\begin{tabular}{lllll}
\hline TYPE & NUMBER & TOTAL EMPLOYMENT & \multicolumn{2}{l}{ \% TURNOVER DUE TO } \\
PARK & TOURIST/LOCAL RATIO & $12 \%$ & $68: 32$ \\
\hline Accommodation units & 5 & 78 & $8.8 \%$ & $37: 63$ \\
Curio shops & 5 & 39 & $15 \%$ & $32: 68$ \\
Food and restaurants & 11 & 140 & $15 \%$ & $60: 40$ \\
Tourism services & 2 & 7 & $8 \%$ & $20: 80$ \\
Retailers & 55 & 308 & $20 \%$ & $40: 60$ \\
Transport and petrol stations & 4 & 138 & $16.7 \%$ & $20: 80$ \\
Wholesalers & 3 & 77 & $9.3 \%$ & $11: 89$ \\
Manufacturers & 4 & 23 & & \\
\hline
\end{tabular}

TABLE 10

Influence of the Karoo NP on the community

\begin{tabular}{|c|c|c|c|c|c|c|c|}
\hline \multirow{2}{*}{ STATEMENT } & \multicolumn{2}{|c|}{ VERY NEGATIVE } & \multicolumn{3}{|c|}{ NO EFFECT } & \multicolumn{2}{|c|}{ VERY POSITIVE } \\
\hline & -3 & -2 & -1 & 0 & 1 & 2 & 3 \\
\hline Personal quality of life & $1 \%$ & $2 \%$ & $1 \%$ & $21 \%$ & $8 \%$ & $25 \%$ & $42 \%$ \\
\hline Beaufort West community & $4 \%$ & $3 \%$ & $2 \%$ & $10 \%$ & $10 \%$ & $28 \%$ & $44 \%$ \\
\hline
\end{tabular}

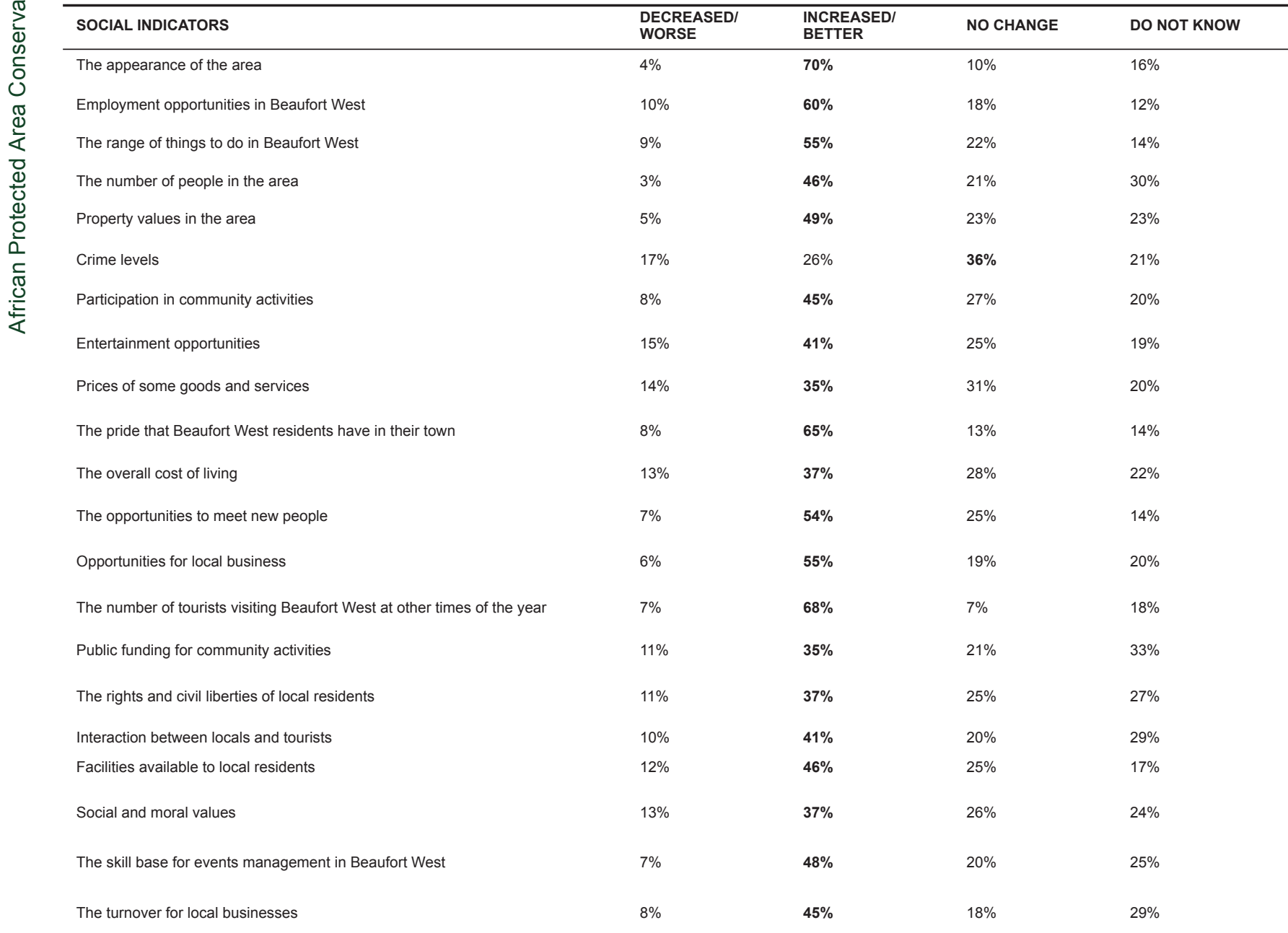


First, if one compares this research with the study conducted by Saayman \& Saayman (2006a) in the Addo Elephant National Park, which is the only other case study in South Africa in which the same method of research was applied, the following differences become apparent: businesses in Beaufort West clearly cannot distinguish between tourists and local shoppers, and this is because many tourists pass through Beaufort West when travelling and most tourists only make use of the Karoo $\mathrm{NP}$ as a 'stop-over' destination. In the case of Addo Elephant National Park, the main drawcard in the area is the park, which is not the case in Beaufort West. Added to this is the fact that the Addo Elephant National Park is surrounded by smaller villages, for example, Addo and Paterson, where the locals know each other, which is less of a feature in Beaufort West.

Second, the multipliers created by the matrix inversion process are higher than those of the Addo National Park, which is to be expected given that Beaufort West is a much larger town than Addo, Paterson or Kirkwood (see Saayman \& Saayman, 2006a). The income multiplier generated by the matrix inversion process for groups holidaying in chalets is again in line, but slightly higher for camping groups than that found for the Addo Elephant Park. The rationale behind the higher multipliers is intuitively correct, since Beaufort West is not situated close to any larger town that creates more extensive leakages in terms of employment creation and spending by households.

Third, the fact that the park borders on Beaufort West and that Karoo NP staff are living in the community has a positive impact on community perceptions of the park.

Fourth, the smaller the operation (for example, accommodation, tourist numbers and activities), the lesser the socio-economic impact. Hence the size of operations definitely plays a role. National parks, and specifically the Karoo NP, should offer more activities, more species and more accommodation facilities, where possible, to get tourists to stay longer and spend more money. This will increase the magnitude of the socio-economic impact.

Fifth, the socio-economic impact of a tourist product is influenced mainly by length of stay and magnitude of spending, as indicated by Page (2007), Dwyer, Forsyth and Spurr (2005) and Mathieson and Wall (1982). As has been mentioned, these aspects are influenced by aspects such as variety and scope of activities, in other words what does the park offer or what can the region offer tourists to do? The fewer species and variety of species the park offers, the shorter the stay. This applies to activities as well. In the case of the Karoo NP, the number of species is significantly lower than in other national parks, such as the Addo Elephant Park, the Kruger National Park and the Mokala National Park.

Lastly, improved communication can also increase awareness among tourists, businesses and other product owners of what the park wants to achieve and how the community needs to work together to achieve this. According to Andriotis (2006), Gursoy, Jurowski and Uysal, (2002), Page et al. (2002), Slabbert (2007), Saayman (2000), Fredline and Faulkner (2001), and Urtasun and Gutiérrez (2005), the following are the most important in social impact analysis: involvement in the park, community attachment, contact with tourists and state of local economy. Therefore, to grow the socio-economic impact of the park it is of paramount importance that tourism products in the region are developed and promoted, and that the community must be informed regularly. Added to this, Coetzee (2004) has pointed out that, from a socio-economic and sustainability point of view, community perceptions are important. In this regard, communication plays an important role, since it creates perceptions (Streuders 2008)

\section{CONCLUSION}

The purpose of this research was to determine the socioeconomic impact of the Karoo National Park (Karoo NP). This was done by estimating the economic impact of the Karoo NP on the local economy. Secondly, the impact of tourism business development in the Karoo district was estimated, as well as the way in which these businesses benefited the community. Thirdly, the employment generated as a result of the Karoo NP and tourism activities in the area was determined, as well as the community's satisfaction with the Karoo NP.

The results indicated that the Karoo NP has an impact on employment, production and general income in the region, but not to as significant an extent as documented for the Addo Elephant National Park. Only 4\% of the businesses owe their existence to the Karoo NP, yet many of these businesses rely on tourists' spending - which might be an indication that the influence of the Karoo NP on tourism activity in the area was not taken into account by these businesses. Guest houses and bed-and-breakfast establishments indicated that they owed $12 \%$ of their turnover to the Karoo NP. Curio shops indicated that $8.8 \%$ of their business was due the Karoo NP, with restaurants indicating a $15 \%$ contribution by the park. Retailers and service stations indicated that they owed $8 \%$ and $20 \%$ respectively of their turnover to the Karoo NP, and tourism and recreation services estimated this contribution at $15 \%$. It would be beneficial for park management to increase communication between businesses in the area, as well as with the community by means of a park forum. Both businesses and the community need to understand what the aims and objectives of the park are.

The results also support the concern that rural areas usually face high leakages, and thus the local economy does not benefit to its full potential. However, the impact is smaller than in the case of the Addo Elephant National Park, as Beaufort West is not situated close to any larger towns, such as Port Elizabeth and George, where more extensive leakages are created in terms of employment and spending by households. However, in terms of employment creation, the fact that $98 \%$ of all workers live in the area is an indication that the benefits of the Karoo NP reach the local community and that it certainly contributes towards social upliftment in the vicinity. Park management could also consider a local 'Wildcard' (the latter is a loyalty card that tourists buy and gives free access to national parks for a period of one year that can be renewed) in order to increase the number of day visitors. Added to this, the Park could consider open days when communities are invited to visit the park free of charge and Park management can then interact with the visitors.

With regard to future research, it is important to examine whether the existence of the Karoo NP changed tourism patterns to Beaufort West. The same research should also be conducted in other national parks, since this research clearly showed how two national parks, namely the Karoo National Park and Addo Elephant National Park, differ in their socio-economic impacts, and thus offer important lessons to be learned.

\section{ACKNOWLEDGEMENTS}

The authors would like to acknowledge Glenn Phillips from SANParks, for financial assistance, as well as the Karoo National Park manager. The NRF provided financial assistance. The anonymous reviewers are thanked for their invaluable input and comments.

\section{REFERENCES}

Andriotis, K., 2006, 'Hosts, guests and politics: Coastal resorts morphological change', Annals of Tourism Research 33, 10791098.

Coetzee, W.J.L., 2004, 'An integrated sustainable tourism development strategy for the Vredefort Dome as a World Heritage Site', PhD dissertation, North-West University. 
Department of Local Government and Housing, 2006, National Imbizo Focus Week. Pre-Imbizo Report, Beaufort West Municipality, Beaufort West.

Dwyer, L. Forsyth, P. \& Spurr, R., 2005, 'Economic impacts and benefits of sport events: A CGE perspective', in J. Allen (ed.), The impacts of events: International Event Research conference proceedings, Sydney, Australia, July 13-14, 2005, n.p.

Fauzi, A. \& Buchary, E.S., 2002, 'A socio-economic perspective of environmental degradation at Kepulauan Seribu Marine National Park, Indonesia', Coastal Management 30, 167-181.

Fredline, E. \& Faulkner, B., 2001, 'Residents' reactions to the staging of major motor sport events within their communities: A cluster analysis', Event Management 7, 103114.

Fredline, L., Jago, L. \& Deery, M., 2003, 'The development of a generic scale to measure the social impact of events', Event Management 8, 23-37.

Govender, Y., Jury, M.R., Mthembu, A., Hatesse, S. \& Bulfoni, E., 2005, 'Socio-economic status and development potential for a rural community on the Maputaland Coast of South Africa', South African Geographical Journal 87(1), 37-42.

Gursoy, D., Jurowski, C. \& Uysal, M., 2002, 'Resident attitudes: a structural modeling approach', Annals of Tourism Research 31(3), 495-516.

Loader, J.A., 1994, 'National parks and social involvement - an argument', Koedoe 37(1), 137-148.

Macleod, D.V.L., 2001, 'Parks or people: National parks and the case of Del Este, Dominican Republic', Progress in Development Studies 1(3), 221-235.

Mathieson, A. \& Wall, G., 1982, Tourism: Economic, physical and social impacts, Longman Group Limited, London.

Municipal Demarcation Board, South Africa, 2006, 'Municipal profile', viewed from http://www.demarcation.org.za/ municprofileonline/websiterouter.aspx?http://www demarcation.org.za/municprofileonline/index.aspx.

Myburgh, E. \& Saayman, M., 2002, Ecotourism in action: Guidelines and principals, 2nd edn., PU for CHE, Potchefstroom.

Nkungwana, M., 2007, Beaufort West Integrated Development Plan Final Document, Beaufort West Municipality, Beaufort West.

Page, S.J., 2007, Tourism management: Managing for change, 2nd edn., Butterworth-Heinemann, Oxford.

Page, S.J., Brunt, P., Busby, G. \& Connell, J., 2002, Tourism: A modern synthesis, Thomson, London.

Pelser, A., 2003, 'Omgewingsbewaring in ' $n$ nuwe era: ' $n$ nis vir die geestes- en sosiale wetenskappe', Tydskrif vir Geestesweetenskappe 43(3/4), 164-176.

Saayman, M., 2000, En route with tourism, 2nd edn., Leisure Publications, Potchefstroom
Saayman, M. \& Bothma, L., 2007, A marketing profile of visitors to the Karoo National Park, North-West University, Potchefstroom.

Saayman, M. \& Fouché, M., 2007, Executive summary of research profiles of selected National Parks in South Africa, North-West University, Potchefstroom.

Saayman, M. \& Saayman, A., 2004, 'Economic impact of cultural events', South African Journal for Economic and Management Sciences 7(4), 629-642.

Saayman, M. \& Saayman, A., 2006a, 'Creating a framework to assess the economic contribution of National Parks in South Africa: The case of the Addo Elephant National Park', Tourism Economics 12(4), 619-633.

Saayman, M. \& Saayman, A., 2006b, 'Estimating the economic contribution of visitor spending in the Kruger National Park to the regional economy', Journal of Sustainable Tourism 14(1), 67-81.

Slabbert, E., 2007, 'The social impact of tourism', in M. Saayman (ed.), En route with tourism, 3rd edn., pp. 149-177, Leisure Publications, Potchefstroom.

South African National Parks, 2007, 'South African National Park - Karoo National Park', viewed 17 January 2008 from http://www.sanparks.org/parks/Karoo.

StatsSA, 2007, 'Statistics South Africa', viewed 28 June 2007 from http://www.statssa.gov.za.

Streuders, C., 2008, 'Communication efficacy of Karoo National Park', Master's thesis, North-West University.

Trochim, W.M., 2006, The research methods knowledge base, 2nd edn., Atomic Dog Publishing, Cincinnati.

Tustin, D.H., Ligthelm, A.A., Martins, J.H. \& Van Wyk, H., 2005, Marketing research, University of South Africa Press, Pretoria.

Urtasun, A. \& Gutiérrez, I., 2005, 'Tourism agglomeration and its impact on social welfare: An empirical approach to the Spanish case', Tourism Management 27, 901-912.

United Nations (UN), 1999, Studies in methods: Handbook of national accounting. Handbook of input-output table compilation and analysis, Series F, No. 74, United Nations, New York.

Van der Merwe, L.H., 2008, 'The socio-economic impact of Klein Karoo National Arts Festival in Oudtshoorn', MCom thesis, North-West University.

Vaughan, D.R., Farr, H. \& Slee, R.W., 2000, 'Estimating and interpreting the local economic benefits of visitor spending: An explanation', Leisure Studies 19, 95-118.

Walpole, M.J. \& Goodwin, H.J., 2000, 'Local economic impacts of Dragon tourism in Indonesia', Annals of Tourism Research 27(3), 559-576 